\title{
Compósitos de $\mathrm{Al}_{2} \mathrm{O}_{3} / \mathrm{ZrO}_{2}$ recobertos com hidroxiapatita dopada com íons $\mathrm{Ag}$
}

\section{$\left(\mathrm{Al}_{2} \mathrm{O}_{3} / \mathrm{ZrO} \mathrm{O}_{2}\right.$ composites coated with hydroxyapatite doped with $\mathrm{Ag}$ ions)}

\author{
J. J. Pierri' ${ }^{1,2}$, E. M. J. A. Pallone ${ }^{3}$, E. B. Roslindo ${ }^{2}$, R. Tomasi ${ }^{1}$, E. C. S. Rigo ${ }^{3}$ \\ ${ }^{1}$ Departamento de Engenharia de Materiais - DEMa, Universidade Federal de S. Carlos - UFSCar \\ Rod. Washington Luiz, km 235, C.P. 676, S. Carlos, SP, 13565-905 \\ ${ }^{2}$ Faculdade de Odontologia de Araraquara - UNESP \\ ${ }^{3}$ Universidade São Francisco, USF, PPG-ECM \\ Rua Alexandre R. Barbosa, 45, Itatiba, S.P. 13251-900 \\ eliana.rigo@saofrancisco.edu.br
}

\begin{abstract}
Resumo
Os compósitos de $\mathrm{Al}_{2} \mathrm{O}_{3} / \mathrm{ZrO}_{2}$ são indicados para desempenhar funções estruturais dentro do organismo em decorrência de suas qualidades mecânicas, podendo ser otimizados mediante a obtenção de uma camada de material bioativo. O método biomimético propõe a obtenção dessa camada mediante a utilização de solução sintética que simula o plasma sanguíneo. Porém, isso não impede que a presença desses materiais no corpo interfira no mecanismo de defesa, além de influenciar nas doses de antibióticos necessárias. Uma maneira de prevenção e tratamento de infecções microbianas é a utilização de sais de prata, neste caso sendo incorporados juntamente com a camada usada. O presente trabalho otimizou o processamento de compósito ZTA (alumina tenacificada por zircônia ) e da obtenção da camada com características bioativas e bactericidas. O método de produção, bem como de recobrimento dos compósitos, foram eficientes nas condições estudadas e a morfologia da camada bioativa sofreu alteração quando imersa na solução de $\mathrm{AgNO}_{3}$, apresentando a formação de fosfato de prata.
\end{abstract}

Palavras-chave: $\mathrm{Al}_{2} \mathrm{O}_{3}, \mathrm{ZrO}_{2}$, compósito, recobrimento biomimético, $\mathrm{AgNO}_{3}$.

\begin{abstract}
$\mathrm{Al}_{2} \mathrm{O}_{3} / \mathrm{ZrO} \mathrm{O}_{2}$ composites are indicated to play structural functions inside the organism due to their mechanical qualities, being able to be optimized by means of the attainment of a layer of bioactive material. The biomimetic method considers the attainment of this layer using a synthetic solution that simulates the body fluid. However, this does not prevent that these materials in the body interfere with the defense mechanism, besides influence in the necessary doses of antibiotics. A way of prevention and treatment of bacterial infections is the use of silver salts, in this case being incorporated to the coating. The present work optimized the processing of zirconia-toughened alumina (ZTA) composites with bioactive and bacterial characteristics. The production method, as well as the implant coatings, had been efficient in the studied conditions and the morphology of the bioactive layer on the composite suffered alteration when immersed in the $\mathrm{AgNO}_{3}$ solution, with the formation of silver phosphate.
\end{abstract}

Keywords: $\mathrm{Al}_{2} \mathrm{O}_{3}, \mathrm{ZrO}_{2}$, composite, biomimetic coating, $\mathrm{AgNO}_{3}$.

\section{INTRODUÇÃO}

Devido ao elevado módulo de elasticidade, elevada resistência à compressão, inércia química e a boa relação entre resistência à fratura e ao desgaste, os materiais cerâmicos têm chamado a atenção no mundo dos biomateriais [1]. Soluções com base em metais têm sido questionadas quanto aos problemas de desgaste, toxicidade de elementos de liga e corrosão que têm apresentado, abrindo novas frentes de pesquisas na área voltada para materiais cerâmicos, como é o caso da alumina [2,3] que, apesar da boa estabilidade in vivo, ainda apresenta certo comprometimento como implante, devido à sua baixa resistência e tenacidade à fratura.

Com o intuito de agregar às boas propriedades da alumina uma maior resistência e tenacidade à fratura, cerâmica ZTA (alumina tenacificada por zircônia ) [4] vêm sendo extensivamente estudadas, pois proporcionam maior resistência ao desgaste e à propagação de trincas, além de excelente biocompatibilidade dos constituintes, tornando-as muito atraentes em aplicações ortopédicas [5-7].

Em decorrência da transformação martensítica da zircônia nos compósitos denominados ZTA, é possível obter um aumento na tenacidade à fratura; entretanto, a heterogeneidade e tamanho de grãos da microestrutura final podem comprometer estes benefícios $[8,9]$.

Os materiais cerâmicos como alumina e zircônia são classificados como bioinertes e/ou biotoleráveis com elevada resistência mecânica, quando comparados com os materiais bioativos. Porém, pelo fato de serem materiais bioinertes e/ou biotoleráveis, não são capazes de ligar-se ao tecido 
ósseo. Desenvolver um método de recobrimento eficaz e que garanta a formação de uma camada de biocerâmica que concorde com as exigências do setor médico-odontológico é o maior desafio dos pesquisadores envolvidos com os recobrimentos bioativos [10].

Dentre as diversas técnicas estudas e propostas para este fim, o recobrimento biomimético se destaca pela otimizada ligação formada entre o substrato e a biocerâmica que o recobre, além da possibilidade de formação de camada bioativa sobre diversos materiais [11-13].

Mesmo obtendo um material com características desejáveis para ser implantado, com excelentes propriedades mecânicas e com uma resposta de interação química com o corpo, ainda assim o corpo reage inicialmente ao processo de implantação fazendo com que esses materiais possam interferir no mecanismo de defesa natural do organismo contra possíveis infecções. Além disso, em decorrência do ato cirúrgico há necessidade de utilização de antibióticos que normalmente são ministrados via oral em doses relativamente elevadas. Em alguns casos essa medida não impede que ocorra problemas mais graves e em alguns casos acaba ocorrendo a remoção do implante [14-16].

A administração de antibióticos em muitos casos não consegue ser efetiva, pois ocorre a formação de uma camada circundando ao implante e esta camada acaba agindo como uma barreira para que esse antibiótico atue no local da infecção. Neste caso a solução seria aumentar a dose desses medicamentos. Vários métodos estão sendo pesquisados para que possa haver liberação dos antibióticos no local do processo de infecção [14-19].

Uma maneira de prevenção e tratamento de infecções microbianas é mediante a utilização de sais de prata. No entanto, sabe-se que os íons Ag podem ser inativos em decorrência da complexação com o meio fisiológico [20]. Muitos materiais inorgânicos com efeitos bactericidas contendo íons Ag estão sendo pesquisados e alguns deles já estão sendo usados comercialmente para esse fim [14-20].

O presente trabalho otimizou o processamento do compósito ZTA com características bioativas e bactericidas. Neste contexto verificou-se o efeito da dopagem com íons Ag sobre a morfologia e a fase do recobrimento de hidroxiapatita.

\section{MATERIAIS E MÉTODOS}

Para a produção das amostras utilizou-se $\mathrm{Al}_{2} \mathrm{O}_{3}$ (AKP53, Sumitomo Chemical Co., 99,995\% de pureza, tamanho médio de partículas $0,2 \mu \mathrm{m}$ e área superficial específica $\left.13,6 \mathrm{~m}^{2} / \mathrm{g}\right)$ e $\mathrm{ZrO}_{2}$ comercial parcialmente estabilizada com 3\% de ítria (Alfa Aesar, MA,USA, 99,9\% de pureza, tamanho médio de partículas $1 \mu \mathrm{m}$ ). Para este estudo, foram utilizados $15 \%$ em volume de zircônia na alumina pois, segundo vários autores, esta proporção maximiza o ganho em tenacidade minimizando a fragilização por processos de envelhecimento á baixas temperaturas[1, 22]. Os pós foram misturados por $24 \mathrm{~h}$ em moinho de bolas juntamente com $1 \%$ em peso de defloculante poliacrilato de amônia e do ligante álcool polivinílico em meio aquoso [21]. Paralelamente, preparou-se uma placa de gesso com dimensões de 0,1 x 0,1 x 0,05 m. Após secagem em estufa, foi depositada na placa de gesso a suspensão previamente preparada. Por efeito de capilaridade, a água contida na solução foi sugada pela placa de gesso, resultando em uma película do material de interesse.

O método de produção do compósito é uma combinação de colagem por barbotina (slip casting) com colagem por fita (tape casting). Esse método é versátil, pois produz peças no tamanho e formato desejado. Pelo método usado é possível produzir desde pequenas peças com $1 \mathrm{~mm}^{3}$ para implantes em tíbias de pequenos roedores até placas grandes com 300 $\mathrm{mm}^{2}$ para implantes subcutâneo de coelhos e mamíferos superiores.

Com o auxílio de uma lâmina de bisturi, a película foi cortada de acordo com os formatos e dimensões desejados; as amostras obtidas foram então secas em estufa, calcinadas em mufla a $500{ }^{\circ} \mathrm{C}$ por $3 \mathrm{~h}$ para a retirada dos aditivos orgânicos e sinterizadas a $1500{ }^{\circ} \mathrm{C}$ durante $1 \mathrm{~h}$, com taxa de aquecimento de $10{ }^{\circ} \mathrm{C} / \mathrm{min}$. Na seqüência as amostram foram caracterizadas por medidas de densidade aparente pelo método de Archimedes, difração de raios X (DRX) e microscopia eletrônica de varredura (MEV).

\section{Recobrimento biomimético}

Para o recobrimento dos compósitos de ZTA, adotouse 2 etapas: a primeira etapa para a nucleação, que consiste na imersão dos substratos em solução de silicato de sódio (SS), e solução sintética que simula o plasma sangüíneo (SBF), para geração dos núcleos que proporcionarão o crescimento apropriado da camada de apatita. A segunda etapa para a formação e crescimento da camada através da re-imersão do substrato em 1,5 SBF [13]. Os substratos de ZTA foram mantidos em incubadora a $37^{\circ} \mathrm{C}$ por 7 dias. Após esse período de incubação, os substratos foram lavados por imersão em água destilada e deionizada e secos à temperatura ambiente; em seguida, re-imersos em 1,5 SBF e incubados por mais 6 dias a $37^{\circ} \mathrm{C}$, renovando esse 1,5 SBF a cada 2 dias. Ao final desse período foram novamente lavados em água destilada e deionizada e secos à temperatura ambiente.

\section{Incorporação dos íons $\mathrm{Ag}$}

Após a finalização dos recobrimentos, os substratos foram imersos em soluções preparadas com água destilada e $\mathrm{AgNO}_{3}$ de grau analítico com concentração de 100 ppm por $48 \mathrm{~h}$ a $37^{\circ} \mathrm{C}$.

Caracterização dos substratos de ZTA recobertos sem e com adição de íons $A G$

Os substratos foram caracterizados pelas técnicas de difração de raios $\mathrm{X}$ e microscopia eletrônica de varredura com microanálise por espectroscopia por disperßão de energia (EDS) 


\section{RESULTADOS E DISCUSSÃO}

Difração de raios $X$

As peças obtidas de ZTA mostraram-se rígidas, com dimensões esperadas e valores de densidade próximos da densidade teórica do compósito (97,8\%DT). A Fig. 1 mostra os difratogramas de raios $\mathrm{X}$ dos compósitos sem recobrimento e recobertos com hidroxiapatita (Figs. 1a e 1b, respectivamente) e a Fig. 2 os compósitos recobertos com hidroxiapatita com imersão na solução contendo íons Ag. Após a etapa de recobrimento, foi possível identificar $\mathrm{Al}_{2} \mathrm{O}_{3}$, composto majoritário do compósito ZTA $\left(2 \theta=37,8^{\circ} ; 35,2^{\circ}\right.$;

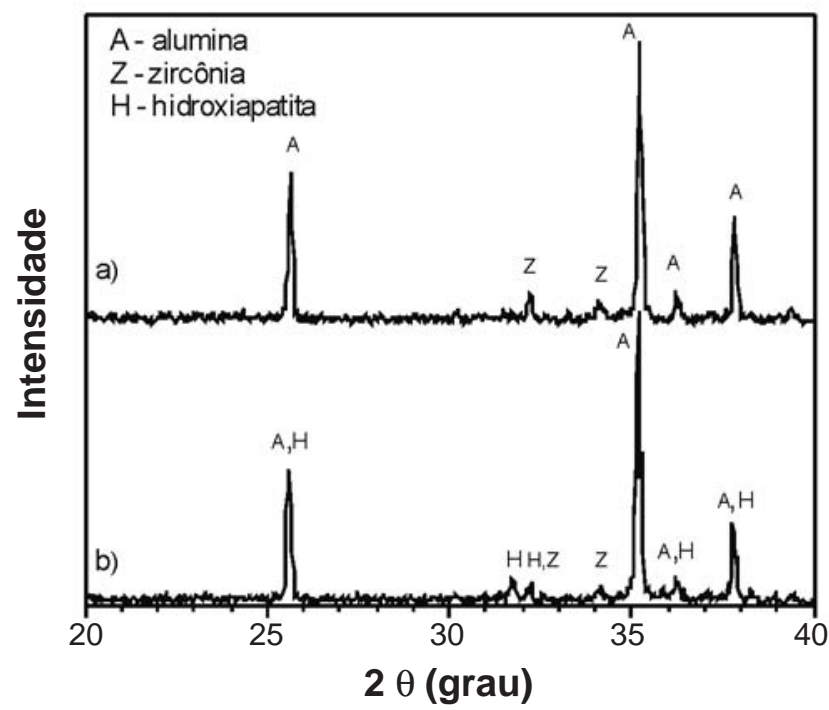

Figura 1: Difratogramas de raios X do compósito de ZTA: a) sem recobrimento; b) com recobrimento de hidroxiapatita.

[Figure 1: X-ray diffraction patterns ZTA composite: a) without coating; b) with hydroxyapatite coating.]

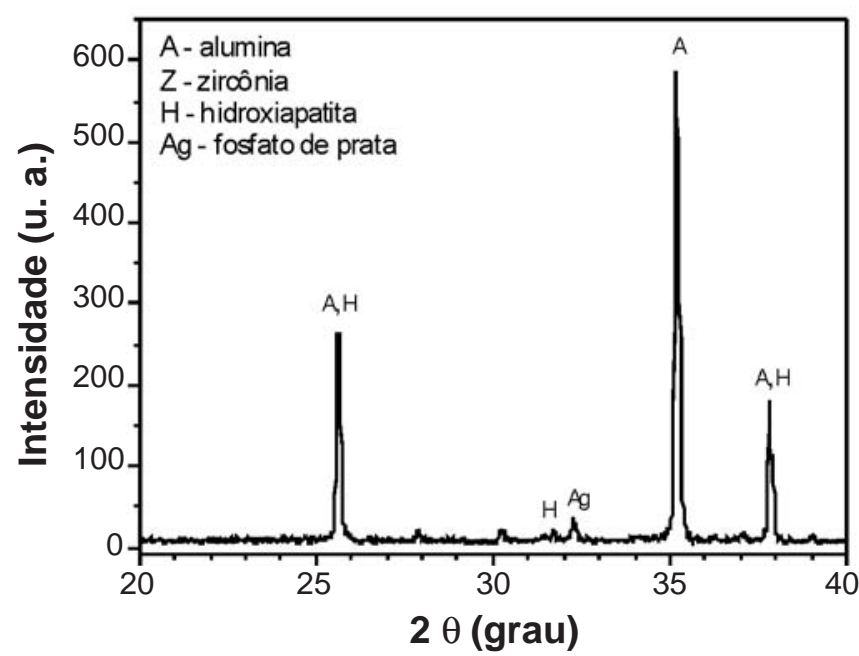

Figura 2: Difratograma de raios $\mathrm{X}$ do compósito de ZTA com recobrimento de hidroxiapatita após imersão na solução de $\mathrm{AgNO}_{3}$. [Figure 2: X-ray diffraction patterns of ZTA composite with hydroxyapatite coating after immersion in $\mathrm{AgNO}_{3}$ solution.] $\left.25,6^{\circ}\right)$ e da HA $\left(2 \theta=36,2^{\circ} ; 34,7^{\circ} ; 31,8^{\circ}\right)$ (Fig. 1$)$.

Após o recobrimento e imersão na solução de $\mathrm{AgNO}_{3}$ com concentração de 100 ppm, observou-se o surgimento de uma fase de fosfato de prata, $\mathrm{Ag}_{4} \mathrm{P}_{2} \mathrm{O}_{7}\left(2 \theta=32,4^{\circ}\right)$ (Fig. 2).

Aquantidade de íons substituídos na camada de hidratação da hidroxiapatita é de aproximadamente $4 \%$ do total de íons Ca na estrutura do cristal [15]. Conseqüentemente, o excesso de íons Ag foi incorporado na fase de um fosfato de prata, comportamento desejável para que a camada possa ter um efeito bactericida.

\section{Microscopia eletrônica de varredura}

As Figs. 3a e $3 \mathrm{~b}$ mostram as micrografias do compósito ZTA obtido. É possível observar a boa dispersão da $\mathrm{ZrO}_{2}$ (pontos claros) na matriz de $\mathrm{Al}_{2} \mathrm{O}_{3}$, comprovando a eficiência no processo de dispersão do pó. Observa-se também uma baixa porosidade residual com tamanhos de grãos de $\mathrm{Al}_{2} \mathrm{O}_{3}$ em torno de 1 a $2 \mu$ m, favorecendo melhoria nas propriedades mecânicas do compósito [7, 21]. Esta porosidade residual observada provavelmente foi causada pela presença maciça de grãos de $\mathrm{ZrO}_{2}$, uma vez que esta fase atua como inibidora do processo de sinterização conforme já observado por vários autores [23, 24].

A Fig. 4 mostra a micrografia obtida por MEV com EDS da superfície da camada de hidroxiapatita depositada sobre o
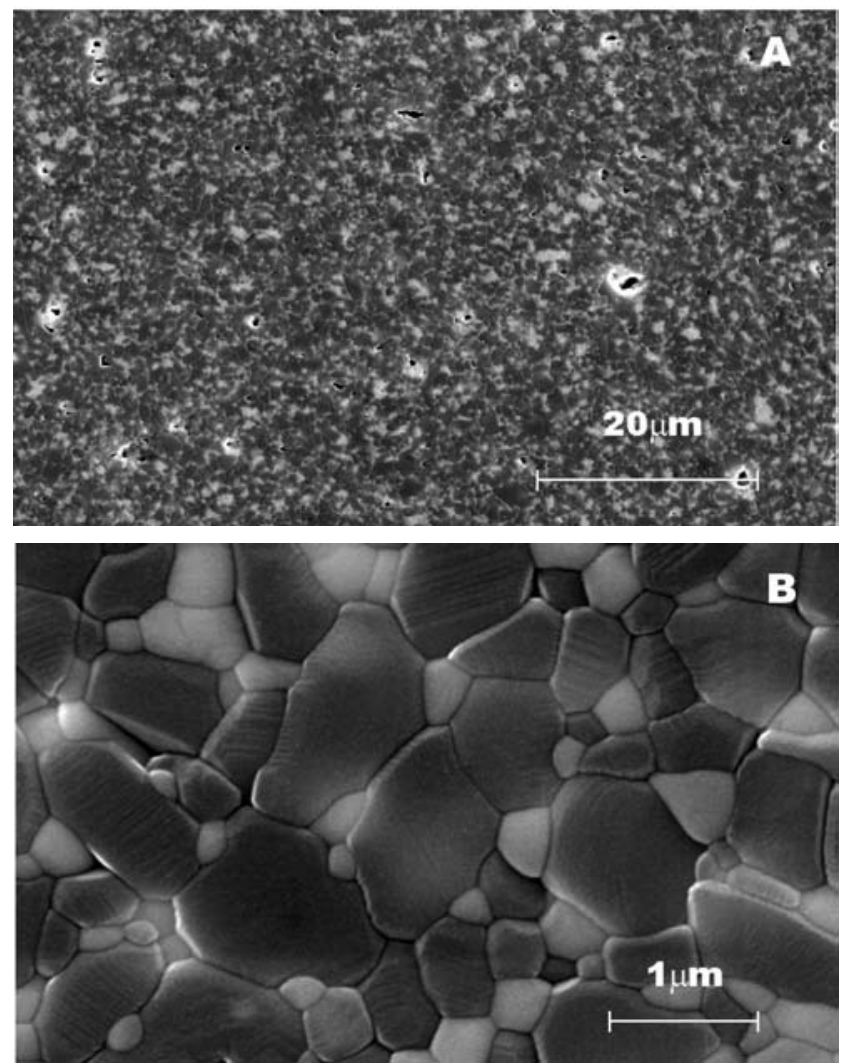

Figura 3: Micrografias obtidas por microscopia eletrônica de varredura do compósito de ZTA (A) visão geral da superfície polida e atacada termicamente e (B) superfície mostrando o tamanho de grãos.

[Figure 3: SEM Micrographs of the ZTA composite: A) general view of the microstructure and B) surface showing size of the grains.] 
compósito de ZTA. Observa-se uma morfologia homogênea, composta por pequenos glóbulos, com tamanhos menores que $2 \mu \mathrm{m}$, caracterizando a formação de uma camada de apatita carbonatada [12,13]. Esses glóbulos foram analisados utilizandose EDS (área especificada) identificando íons $\mathrm{Ca}, \mathrm{P}, \mathrm{Al}, \mathrm{Zr}$, onde os íons Ca e $\mathrm{P}$ confirmam a formação de uma fase de fosfato de cálcio. A formação da hidroxiapatita depende fortemente da concentração dos íons presentes na solução próxima à superfície do substrato, indicando que as condições previamente estabelecidas para o recobrimento foram ideais [13]

A Fig. 5 apresenta o resultado de MEV e EDS do compósito recoberto após imersão na solução de $\mathrm{AgNO}_{3}$. Pode-se observar uma alteração na morfologia da camada, comparada com a morfologia sem imersão. Nesta condição a camada apresentase mais densa, observando-se a presença de pequenas partículas sobre a mesma. A análise por EDS (área especificada) confirma a presença de íons $\mathrm{Ca}, \mathrm{P}, \mathrm{Al}, \mathrm{Zr}$, além do íon $\mathrm{Ag}$.

$\mathrm{O}$ método biomimético utiliza-se do seguinte mecanismo

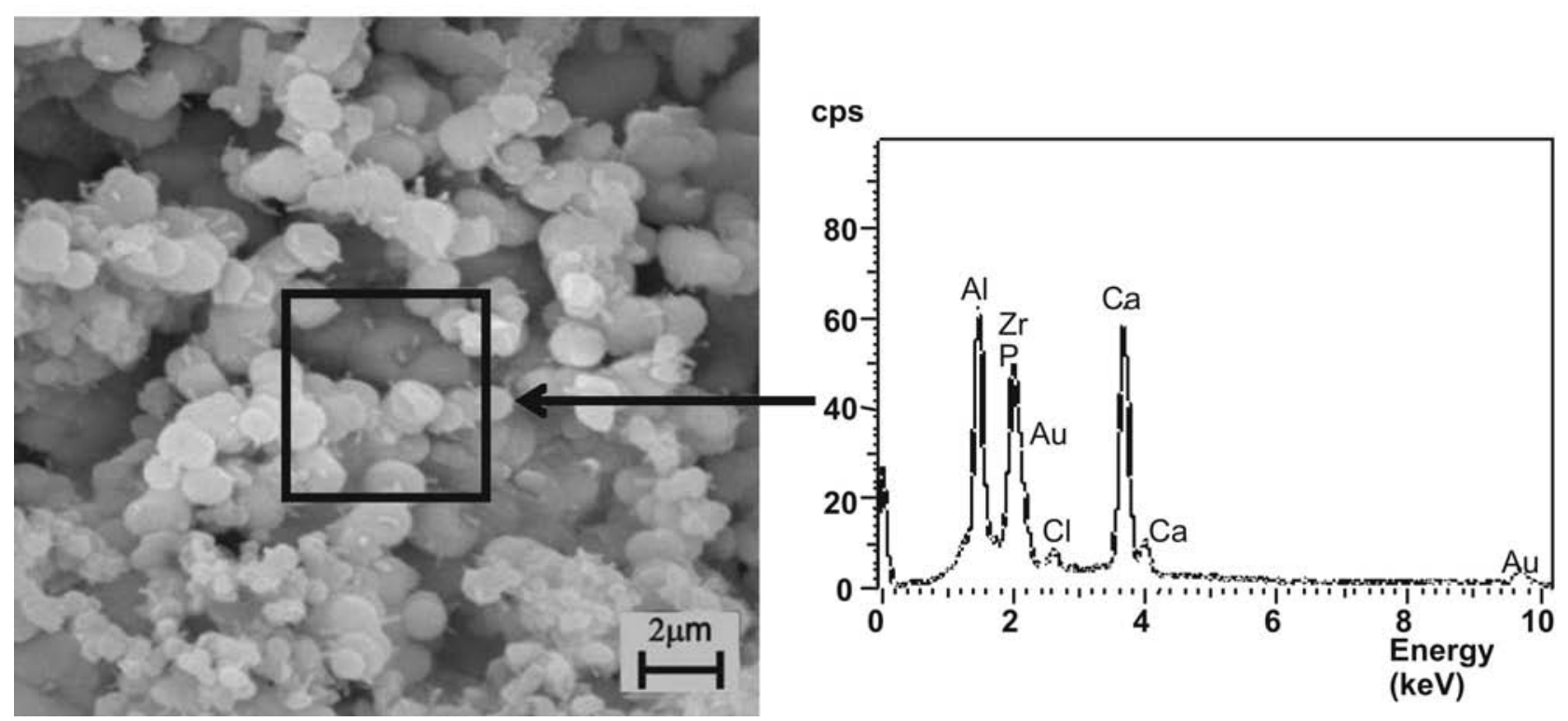

Figura 4: Micrografias obtidas por microscopia eletrônica de varredura dos compósitos de ZTA recobertos e microanálise por espectroscopia de energia dispersiva (EDS) da região especificada.

[Figure 4: SEM Micrographs of the ZTA composite coated and microanalyse energy dispersion spectroscopy (EDS) of the specified region.]

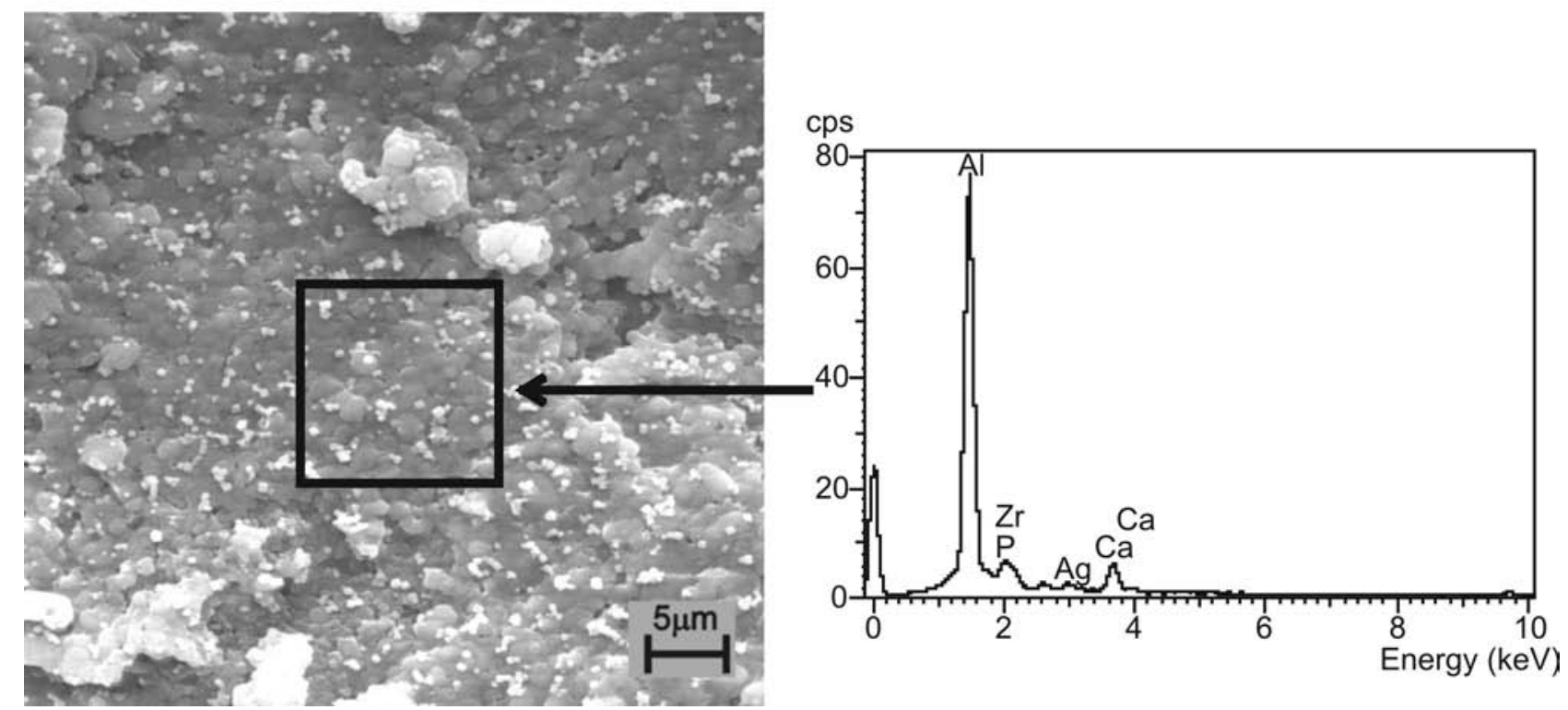

Figura 5: Micrografias obtidas por microscopia eletrônica de varredura dos compósitos ZTA recobertos após imersão na solução de $\mathrm{AgNO}_{3}$ e microanálise por espectroscopia de energia dispersiva (EDS) da região especificada.

[Figure 5: SEM micrographs of the ZTA composite coated after immersion in the $\mathrm{AgNO}_{3}$ solution and energy dispersion spectroscopy (EDS) microanalysis of the specified region.] 
[12]: (1) os íons silicatos presentes no vidro $G$ dissolvemse e se adsorvem sobre o substrato; (2) ocorre a nucleação de HA sobre os íons silicato adsorvidos; (3) os núcleos de HA crescem às custas do SBF supersaturado com relação a HA. Para o substrato de ZTA, a utilização da solução de silicato de sódio atua como um fornecedor de íons silicatos que se transformam em sítios de $\mathrm{Si}-\mathrm{OH}$ sobre a superfície do mesmo, dessa forma a morfologia da superfície do substrato é fundamental para que ocorra a formação de um maior número de núcleos.

Em trabalho recente, foi estudado o comportamento do compósito de zircônia (parcialmente estabilizada com Mg)/ alumina quando imerso em soluções com concentrações de $1 \mathrm{SBF}$ a 1,4 SBF [25]. De acordo com os resultados, é necessário um estágio inicial ao processo de precipitação da camada de hidroxiapatita, ou seja, condições para que possa ocorrer a formação de núcleos. Esse resultado, bem como, o apresentado nesse trabalho, reforça a característica desses tipos de materiais (alumina e zircônia), ou seja, materiais com características biotoleráveis, porém, em condições ideais é possível facilitar a formação de núcleos de apatita e os mesmos crescerem em soluções supersaturadas com relação os íons Ca e P.

A utilização da solução de silicato de sódio em substituição ao vidro bioativo, amplamente utilizado como agente nucleante no método convencional $[12,13]$, atuaram como fornecedores de íons Si que foram adsorvidos sobre a superfície do compósito ZTA. Os resultados apresentados demonstram que a solução de silicato de sódio pode ser utilizada como agente nucleante, pois, os íons silicatos desempenharam sua função e foram adsorvidos sobre a superfície do compósito, para a formação dos grupos silanóis (Si-OH), os responsáveis para que ocorresse a nucleação e posterior precipitação da camada de apatita.

\section{CONCLUSÕES}

As características microestruturais do compósito obtido pelo método utilizado estão de acordo com as propriedades desejadas para este tipo de material - elevada densidade e microestrutura homogênea e com pequeno tamanho de grãos. Os resultados mostraram que o método biomimético utilizado promoveu a deposição de uma camada densa de hidroxiapatita carbonatada sobre o substrato de ZTA. A solução de silicato de sódio, como agente nucleante, mostrou-se efetiva para a formação de uma camada de hidroxiapatita carbonatada. A morfologia da camada inicialmente obtida sobre o substrato de ZTA sofreu alteração quando os mesmos foram imersos na solução de $\mathrm{AgNO}_{3}$. A difração de raios X evidencia a presença de uma fase de fosfato de prata. As características do compósito ZTA, com elevada densidade e microestrutura com pequenos tamanhos de grãos, combinadas com a superfície bioativa via recobrimento biomimético, possibilita sua utilização como material de implante para solicitação mecânica com interação com o tecido vivo. A solução de $\mathrm{AgNO}_{3}$ mostrou-se bastante promissora, podendo conferir propriedades bactericidas aos compósitos recobertos.

\section{AGRADECIMENTOS}

À FAPESP e CNPq pelo suporte financeiro.

\section{REFERÊNCIAS}

[1] S. Deville, J. Chevalier, G. Fantozzi, J. F. Bartolomé, J. Requena, J. S. Moya, R. Torrecillas, L. A. Diaz, J. Eur. Ceram. Soc. 23, 15 (2003) 2975.

[2] G. Willmann, Adv. Eng. Mater. 2, 3 (2000) 114.

[3] G. Willmann, J. Mater. Proc. Techn. 56 (1996) 168.

[4] R. C. Garvie, R. H. Hannink, R. T. Pascoe, Nature 258 (1975) 703.

[5] H. G. Richter, G. Willmann, Brit. Ceram. Trans. 98, 1 (1999) 29.

[6] R. H. J. Hannink, P. M. Kelly, B. C. Muddle, J. Am. Ceram. Soc. 83, 3 (2000) 461.

[7] F. F. Lange, J. Mater. Sci. 17 (1982) 255.

[8] G. Heimke, S. Leye, G. Willmann, Biomaterials 23 (2002) 1539.

[9] M. Yoshimura, T. Noma, K. Kawataba, S. Somiya, J. Mater. Sci. Lett. 6 (1987) 465.

[10] C. Piconi, G. Maccauro, Biomaterials 20 (1999) 1.

[11] E. C. S. Rigo, L. C. Oliveira, L. A. Santos, R. G. Carrodeguas, A. O. Boschi, Rev. Bras. Eng. Biom. 15, 1-2 (1999) 21.

[12] T. Kokubo, H. M. Kim, M. Kawashita, Biomaterials 24, 13 (2003) 2161.

[13] Y. Abe, T. Kokubo, T. Yamamuro, J. Mater. Sci. Mater. Med. 1 (1990) 233.

[14] M. Shirkhanzadeh, M. Azadegan, G. Q. Liu, Mater. Lett. 24 (1995) 7.

[15] Q. L. Feng, T. N. Kim, J. Wu, E. S. Park, J. O. Kim, D. Y. Lim, F. Z. Cui, Thin Solid Films 335 (1998) 214.

[16] J. J. Blaker, S. N. Nazhat, A. R. Boccaccini, Biomaterials 25 (2004) 1319.

[17] D. S. Dunn, S. Raghavan, R. G. Volz, J. Biomed. Mater. Res. 27, 7 (1993) 895.

[18] M. Stigter, K. De Groot, P. Layrolle, Biomaterials 23 (2002) 4143.

[19] J. G. E. Hendriks, J. R. Van Horn, H. C. Van der Mei, H. J. Busscher, Biomaterials 25 (2004) 545.

[20] S. B. Sant, K. S. Gill, R. E. Burrel, Scripta Mater. 41, 12 (1999) 1333.

[21] J. Pierri, E. B. Roslindo, R. Tomasi, E. M. J. A. Pallone, E. C. S. Rigo, J. Non-Cryst. Solids 352, 50-51 (2006) 5279. [22] I. M. G. dos Santos, R. C. M. Moreira, E. R. Leite, E. Longo, J. A. Varela, Ceram. Int. 27 (2001) 283.

[23] G. J. Liu, H. B. Qiu, R. Todd, R. J. Brook, J. K. Guo, Mater. Res. Bull. 33, 2 (1998) 281.

[24] D. Casellas, M. M. Nagl, L. Llanes, M. Anglada, J. Mater. Proc. Tech. 144-143 (2003) 148.

[25] D. A. Cortes, A. A. Nogiwa, J. M. Almanza, S. Ortega, Mater. Lett. 59 (2005) 1352.

(Rec.14/07/2006, Rev. 25/10/2006, Ac. 11/12/2006) 